\title{
A highly efficient rice green tissue protoplast system for transient gene expression and studying light/chloroplast-related processes
}

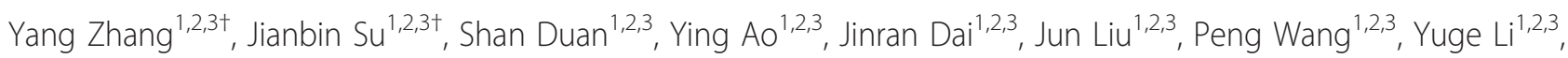
Bing Liu ${ }^{1,2,3}$, Dongru Feng ${ }^{1,2,3}$, Jinfa Wang ${ }^{1,2,3}$ and Hongbin Wang ${ }^{1,2,3^{*}}$

\begin{abstract}
Background: Plant protoplasts, a proven physiological and versatile cell system, are widely used in highthroughput analysis and functional characterization of genes. Green protoplasts have been successfully used in investigations of plant signal transduction pathways related to hormones, metabolites and environmental challenges. In rice, protoplasts are commonly prepared from suspension cultured cells or etiolated seedlings, but only a few studies have explored the use of protoplasts from rice green tissue.

Results: Here, we report a simplified method for isolating protoplasts from normally cultivated young rice green tissue without the need for unnecessary chemicals and a vacuum device. Transfections of the generated protoplasts with plasmids of a wide range of sizes (4.5-13 kb) and co-transfections with multiple plasmids achieved impressively high efficiencies and allowed evaluations by 1) protein immunoblotting analysis, 2) subcellular localization assays, and 3) protein-protein interaction analysis by bimolecular fluorescence complementation (BiFC) and firefly luciferase complementation (FLC). Importantly, the rice green tissue protoplasts were photosynthetically active and sensitive to the retrograde plastid signaling inducer norflurazon (NF). Transient expression of the GFPtagged light-related transcription factor OsGLK1 markedly upregulated transcript levels of the endogeneous photosynthetic genes OsLhcb1, OsLhcp, GADPH and RbcS, which were reduced to some extent by NF treatment in the rice green tissue protoplasts.

Conclusions: We show here a simplified and highly efficient transient gene expression system using photosynthetically active rice green tissue protoplasts and its broad applications in protein immunoblot, localization and protein-protein interaction assays. These rice green tissue protoplasts will be particularly useful in studies of light/chloroplast-related processes.
\end{abstract}

\section{Background}

Transient expression assays allow rapid and high-throughput analysis of genes in plants [1,2] and thus have become widely used for characterization of gene function. Arabidopsis, maize [3] and tobacco protoplasts [4], tobacco leaf epidermal cells [5], tobacco BY-2 cells [6] and onion epidermal cells [7] are commonly used for transient assays in gene expression, protein subcellular localization, protein-protein interaction and protein activity studies.

\footnotetext{
* Correspondence: wanghb@mail.sysu.edu.cn

+ Contributed equally

'State Key Laboratory of Biocontrol, School of Life Sciences, Sun Yat-sen University, Guangzhou 510275, P. R. China

Full list of author information is available at the end of the article
}

Accordingly, several methods for transient gene expression have been developed, such as PEG-mediated protoplast transfection [8], biolistic bombardment [9] and Agrobacterium-mediated transient transformation [10].

Rice is one of the most important cereal crops and a model species for monocotyledonous plants [11]. Some systems such as tobacco and onion have been used for characterization of rice genes [5-7], but they are heterologous systems; the expressed proteins in heterologous systems may exhibit aberrant traits. For example, the encoded proteins of some Arabidopsis genes introduced in tobacco have been shown to be mis-localized [2]. Therefore, many studies have attempted to establish efficient gene expression systems in rice, including tissue-based

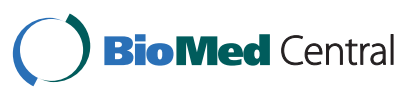


and individual cell-based methods. In tissue-based methods, rice calli, leaves and seedlings are used for transient assays by different approaches. The bombardment approach was successfully used to introduce DNA into rice calli and intact seedlings grown in the dark, but it had poor efficiency and depended on expensive equipment $[12,13]$. Similarly, an electroporation-mediated approach in rice leaves also showed low efficiency [14]. The Agrobacterium-mediated approach yielded higher efficiency and is inexpensive [15-17], but it is difficult to use for subcellular localization and other fluorescence-based analysis, as this method is often associated with a high level of nonspecific autofluorescence. Moreover, the waxy structure of rice tissue is difficult to observe under a fluorescence microscope.

The other type of transient gene expression method used in rice is based on individual cells, including protoplasts and suspension cultured cells $[18,19]$. Green protoplasts provide a suitable system for the quantitative study of many physiological and biochemical processes of plant cells [20], especially light/chloroplast-related processes such as light-induced chloroplasts movement in tobacco $[21,22]$ and light-regulated gene expression in maize [23]. However, suspension cultured cells and etiolated protoplasts are mainly used in transient gene expression assays currently in rice $[18,19,24,25]$. Suspension cultured cells and etiolated protoplasts cultured in the dark are not suitable for investigating many cellular processes, particularly those involving chloroplasts. Some efforts has been made to develop a protoplast transient gene expression system using rice green tissues, which has been used for developmentally regulated plant defense-related gene expression analysis [24], siRNA-mediated silencing [25] and subcellular localization assays [26]. Until now, however, there have been no reported studies of light/chloroplast-related processes using the protoplast system in rice.

Here, we present a simplified and highly efficient method for transient gene expression in protoplasts using young rice green tissue. We applied this method to express one or more constructs for protein immunoblotting, localization and protein-protein interactions assays, particularly for studies of light/chloroplast-related processes.

\section{Results}

\section{Isolation of protoplasts from rice green tissue}

To establish a more physiological and versatile protoplast system than that of suspension cultured cells or etiolated seedlings, we chose normally cultured rice green seedlings as the source material. Briefly, 7 to 10 -day-old rice green seedlings cultured at $26^{\circ} \mathrm{C}$ on $1 / 2 \mathrm{MS}$ medium with a $12 \mathrm{~h}$ light $\left(\sim 150 \mu \mathrm{mol} \mathrm{m}{ }^{-2} \mathrm{~s}^{-1}\right) / 12 \mathrm{~h}$ dark cycle, were used for protoplast isolation (Figure $1 \mathrm{~A}$ and Additional file 1). Stem and sheath tissues from 40-60 rice seedlings were cut into approximately $0.5 \mathrm{~mm}$ strips (Figure $1 \mathrm{~B}$ ). The strips were immediately transferred into $0.6 \mathrm{M}$ mannitol for a quick plasmolysis treatment, followed by enzymatic digestion in the dark with gentle shaking (Figure 1C). The protoplasts were collected by filtration through $40 \mu \mathrm{m}$ nylon meshes. In this isolation protocol, the use of toxic reagents, antibiotics and vacuum was not required.

Our method generated approximately $1 \times 10^{7}$ cells varying from 7 to $25 \mu \mathrm{m}$ in size (Figure 1D), which was sufficient for more than 50 transfection experiments $\left(2 \times 10^{5}\right.$ cells per transfection). The generated rice green tissue protoplasts were above $95 \%$ viable judged by fluorescein diacetate (FDA) staining (Additional file 2). In the rice green tissue protoplasts, the chloroplasts could be easily identified by their typical chlorophyll autofluorescence under a confocal microscope (Chl channels of Figure 2, 3, 4, 5 and 6 ), while they could not be clearly observed in etiolated protoplasts (Figure 2B).

\section{Highly efficient transient transfection of different sized constructs in rice green tissue protoplasts}

After transfection with the 35S::GFP plasmid (pUC-GFP) by using the PEG-mediated transfection approach and incubation for $10 \mathrm{~h}$, the GFP fluorescence was clearly detected both in the cytoplasm and nucleus of the rice green tissue protoplasts and etiolated protoplasts (Figure $2 \mathrm{~A}$ and 2B). Transfection efficiencies of 53-75\% were achieved in the rice green tissue protoplasts, comparable to the $58-77 \%$ in etiolated protoplasts (Figure $2 \mathrm{C}$ and $3 \mathrm{~A}$ ). Moreover, 45-66\% transfection efficiencies were obtained using a large sized $13 \mathrm{~kb}$ binary plasmid CD3-998 in the rice green tissue protoplasts (Figure $3 \mathrm{~B}$ and $3 \mathrm{C}$ ). Even the co-expression of two $13 \mathrm{~kb}$ plasmids (CD3-998 and CD31000, or CD3-966 and CD3-1000) could be easily detected in one random visual field under a confocal microscope with maximum co-transfection efficiencies of 30-45\% (Figure 5). Furthermore, the transfection efficiency was not significantly affected by the transfected plasmid DNA amount in the range of 5-15 $\mu \mathrm{g}$ (data not shown).

To test whether the amount of transiently expressed proteins could be detected in protein assays (e.g., Western blot), we transfected the pUC-bZIP63-YN and pUC-SPYNE constructs into $2 \times 10^{6}$ rice green tissue protoplast cells. The expressed proteins bZIP63-c-myc$\mathrm{YFP}^{\mathrm{N}}$ and c-myc-YFP ${ }^{\mathrm{N}}$ at around $55 \mathrm{kDa}$ and $20 \mathrm{kDa}$, respectively, were clearly detected by monoclonal mouse antibodies to c-myc (Figure 2D). The yield of proteins from $2 \times 10^{6}$ cells was sufficient for at least 10 immunoblot experiments, again indicating that the transfection efficiency was sufficient for protein assays. 

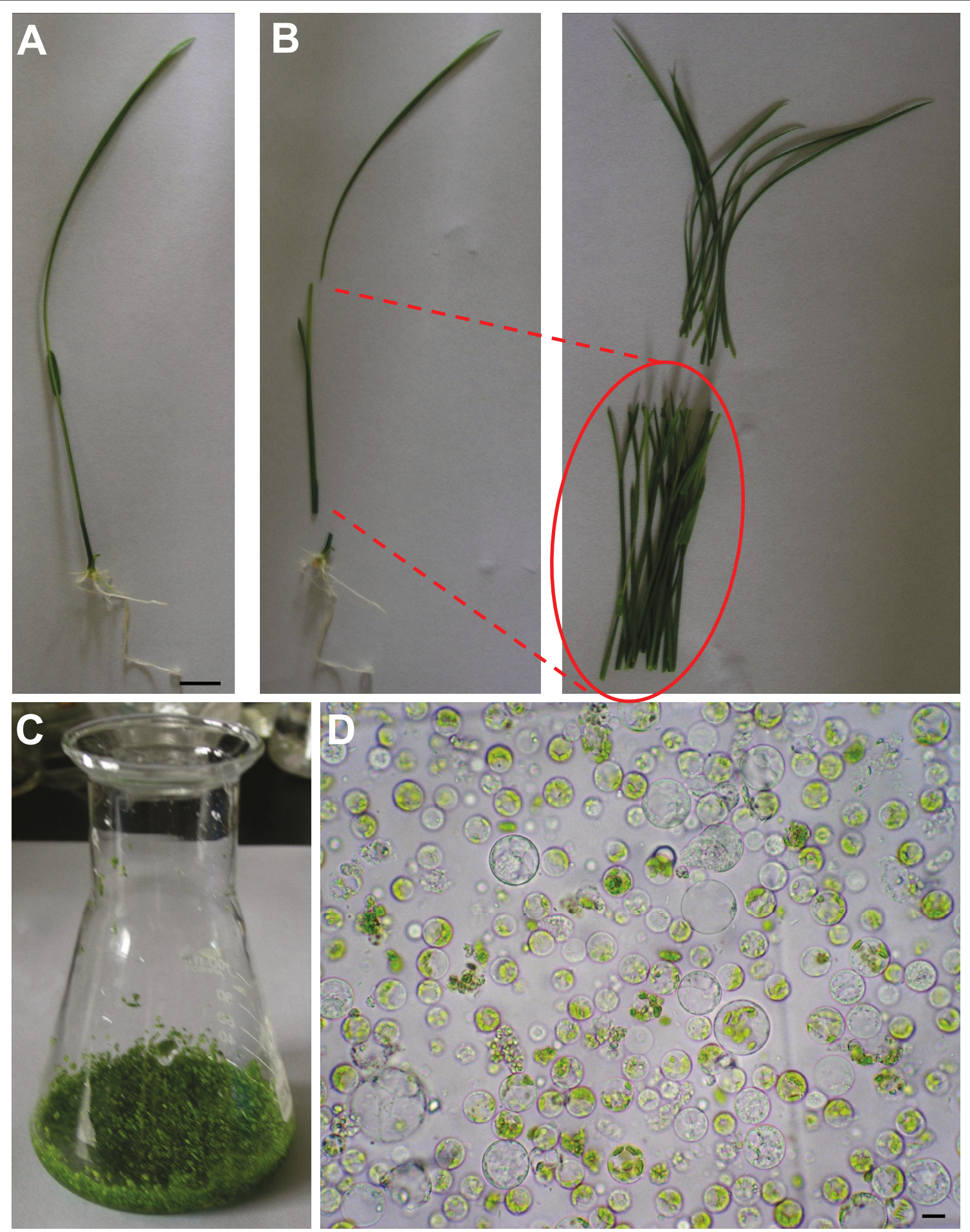

Figure 1 Isolation of protoplasts from rice green tissue. A, A representative healthy 8-day-old rice seedling used for protoplast isolation. Scale bar $=1 \mathrm{~cm}$. B, Red markers indicate the optimal sections of seedlings (stem and sheath) yielding protoplasts. C, Cut strips were treated with $0.6 \mathrm{M}$ mannitol followed by enzymatic digestion. D, Image of protoplasts obtained using a Nikon digital camera under an Olympus microscope with a $40 \times$ objective. Scale bar $=10 \mu \mathrm{m}$. 


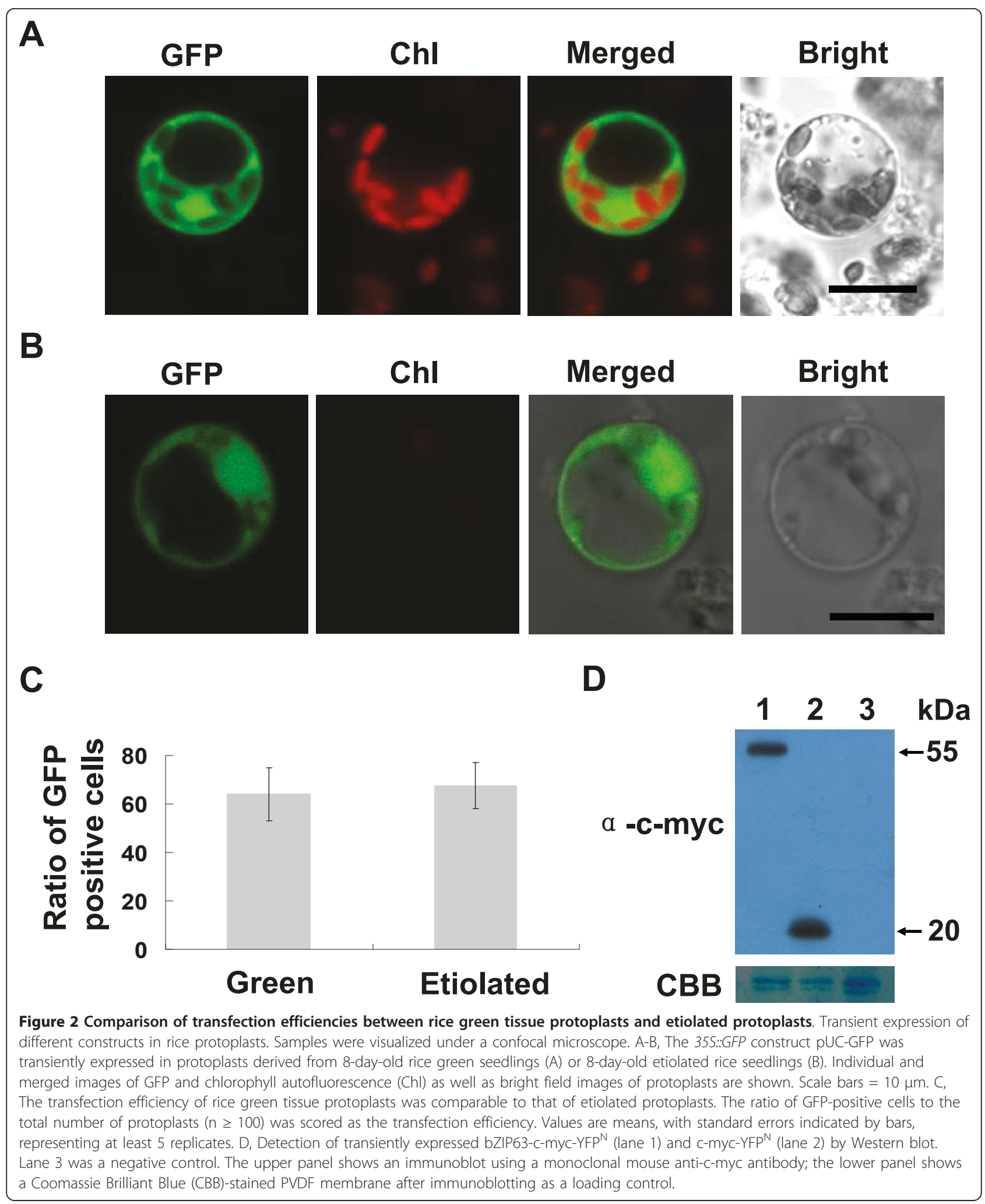




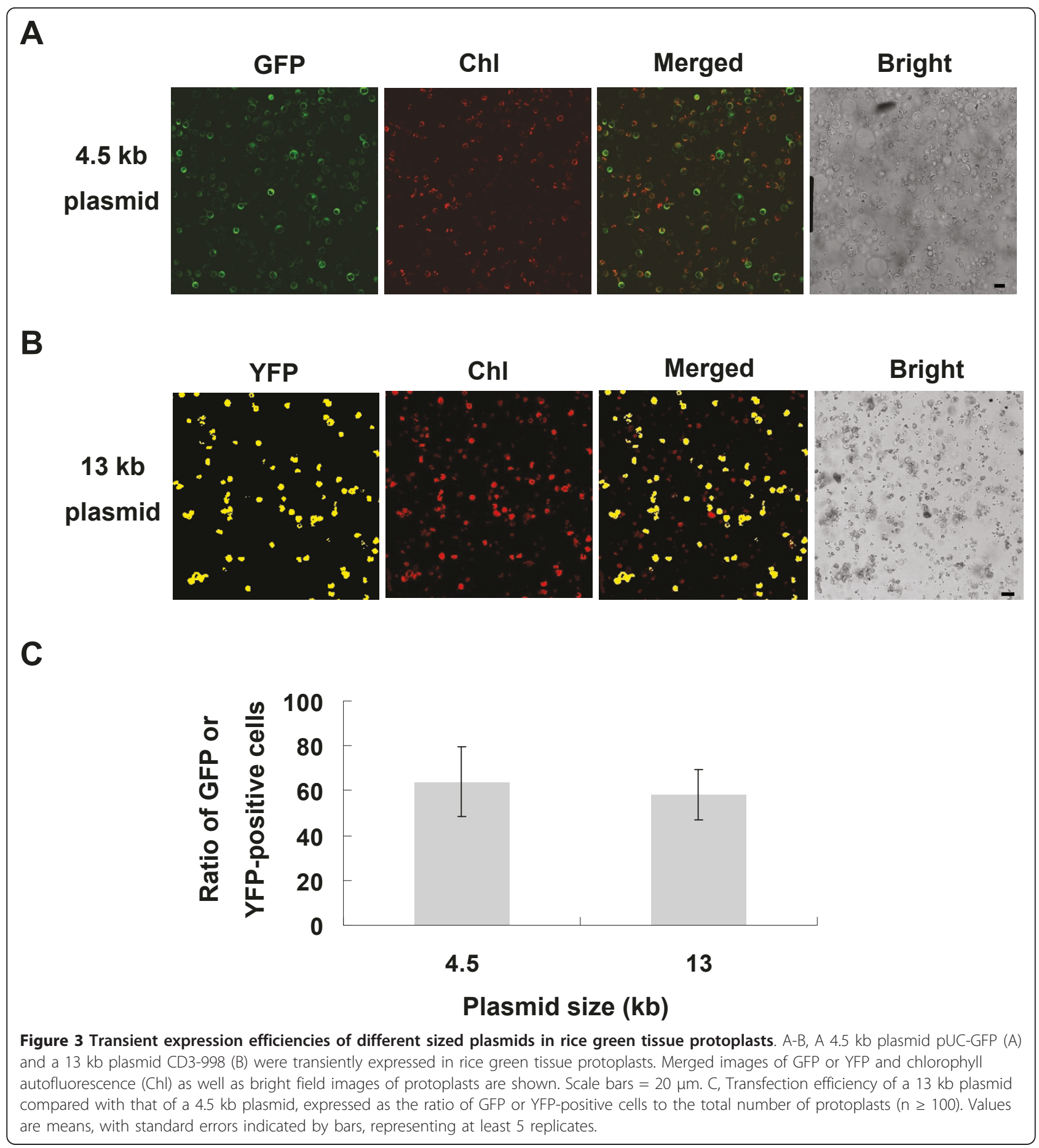

Subcellular localization studies in rice green tissue protoplasts

Four rice proteins, OsRpl6-2, OsTRX m5, OsTRX m2 and BAS1 were expressed as GFP fusion proteins in the rice green tissue protoplast system for subcellular localization studies. As the $\mathrm{N}$-terminal coding region of rice OsRpl6-2 contains mitochondrial targeting information
[27], we observed that OsRpl6-2-YFP was distributed in the cytosol of rice protoplasts as small fluorescent spots resembling mitochondria (Figure 4A). Rice OsTRX m5 (Ostrxm) is a chloroplast $\mathrm{m}$ type thioredoxin [28], and OsTRX m5-GFP appeared to co-localize with the red autofluorescence of chloroplasts (Figure 4B). OsTRX m2 was predicted to be a chloroplast $\mathrm{m}$ type thioredoxin as 


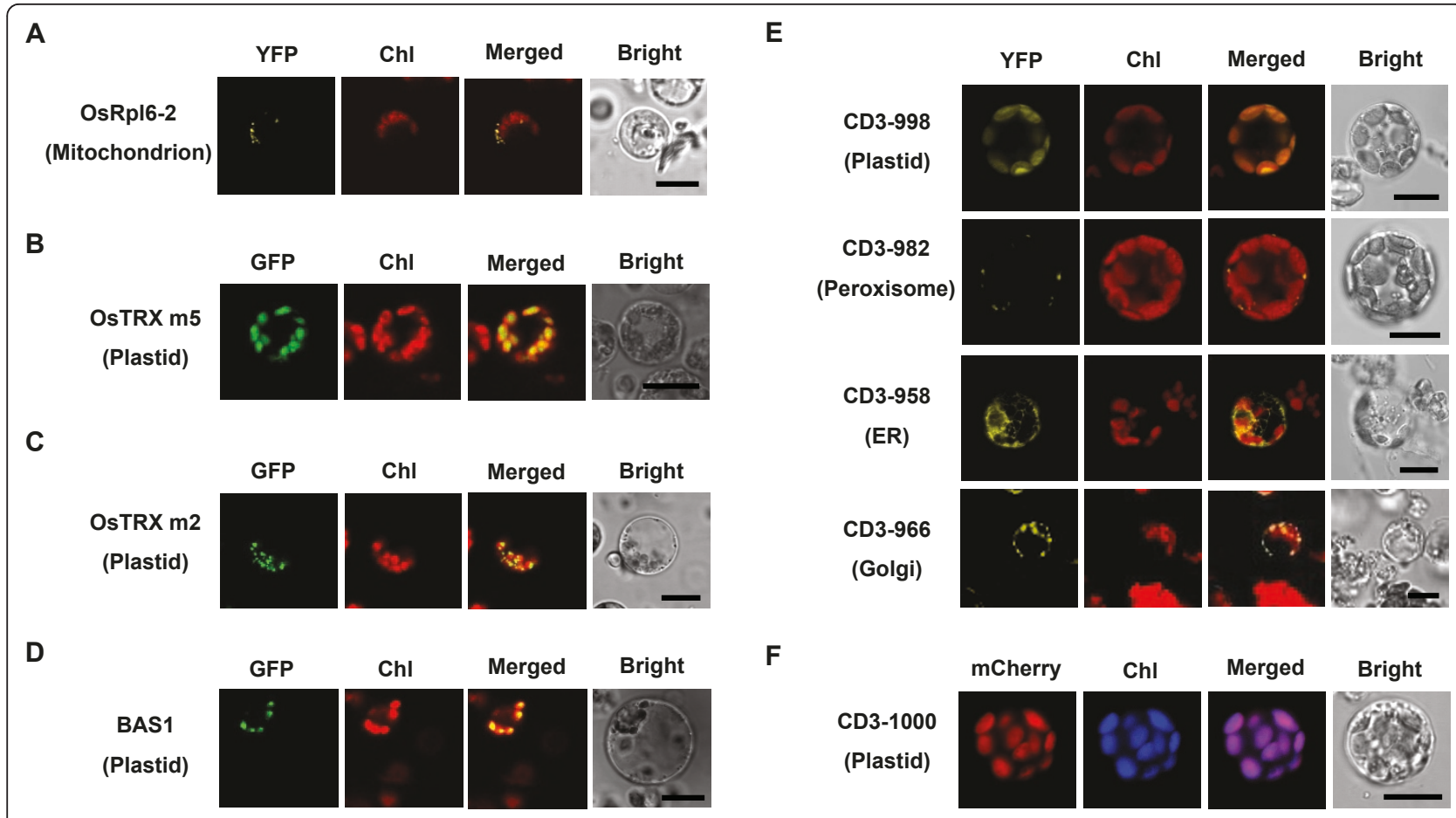

Figure 4 Subcellular localization analysis in rice green tissue protoplasts. Rice proteins and Arabidopsis organelle markers were transiently expressed in rice green tissue protoplasts. A, Rice OsRpl6-2-YFP labeling of mitochondria. B, Rice OsTRX m5-GFP labeling of plastids. C, OsTRX m2-GFP targeted to chloroplasts. D, BAS1-GFP targeted to chloroplasts. E, CD3-998 labeling of plastids; CD3-982 labeling of peroxisomes; CD3958 labeling of the endoplasmic reticulum (ER); CD3-966 labeling of Golgi. F, An mCherry-based plastid marker CD3-1000. Merged images are shown with YFP, mCherry or GFP and chlorophyll autofluorescence (Chl). Bright field images of protoplasts are also shown. Scale bars $=10 \mu \mathrm{m}$.

well (WoLFPSORT, http://wolfpsort.org/; TargetP 1.1 server, http://www.cbs.dtu.dk/services/TargetP/), and OsTRX m2-GFP located to the chloroplasts, exhibiting small fluorescent spots (Figure 4C). BAS1 is a rice chloroplastic 2-Cys peroxiredoxin [29], and BAS1-GFP presented distinctly as one fluorescent spot per chloroplast (Figure 4D). The demonstration of rice proteins targeting to the correct organelles indicated that the rice green tissue protoplast system is suitable for subcellular localization assays.

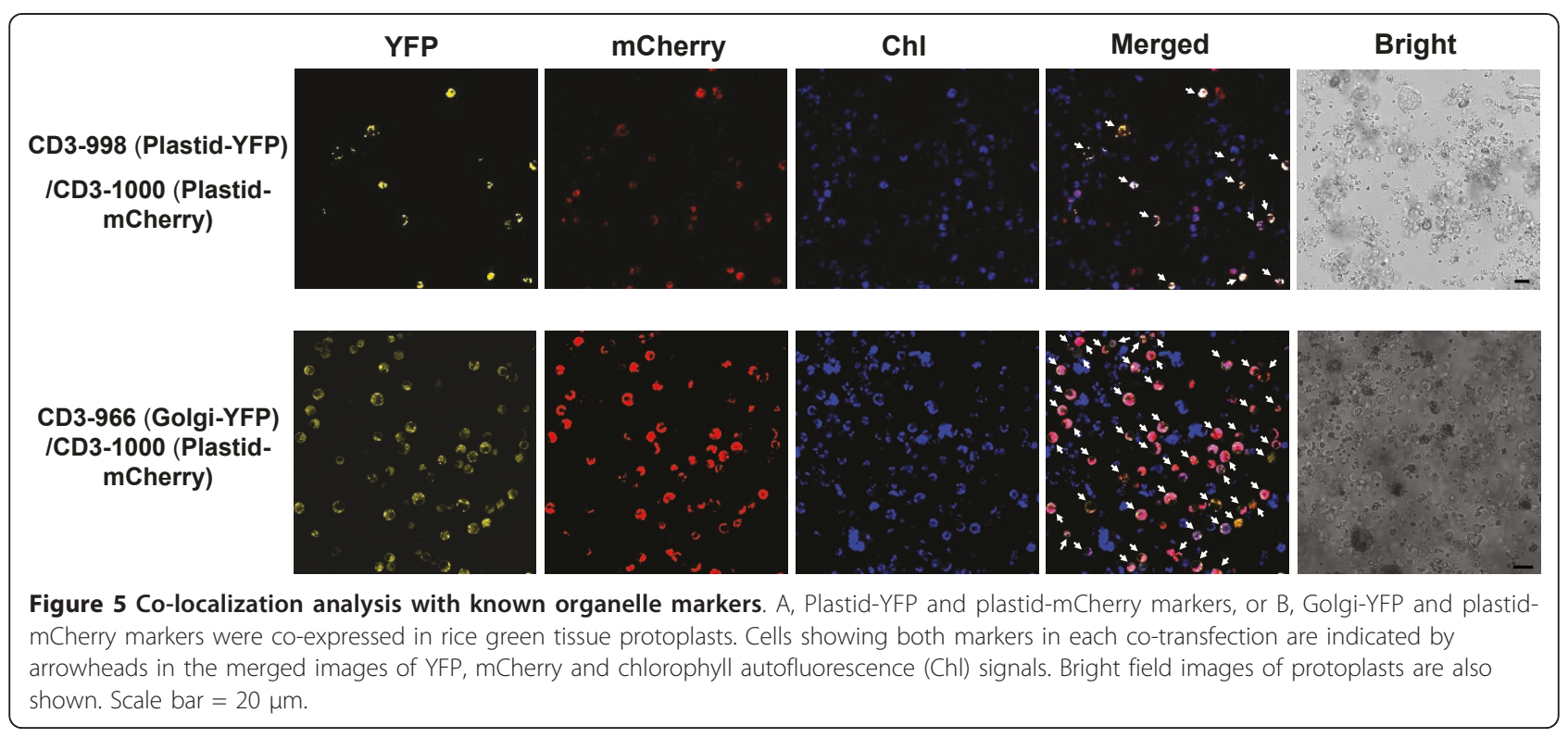




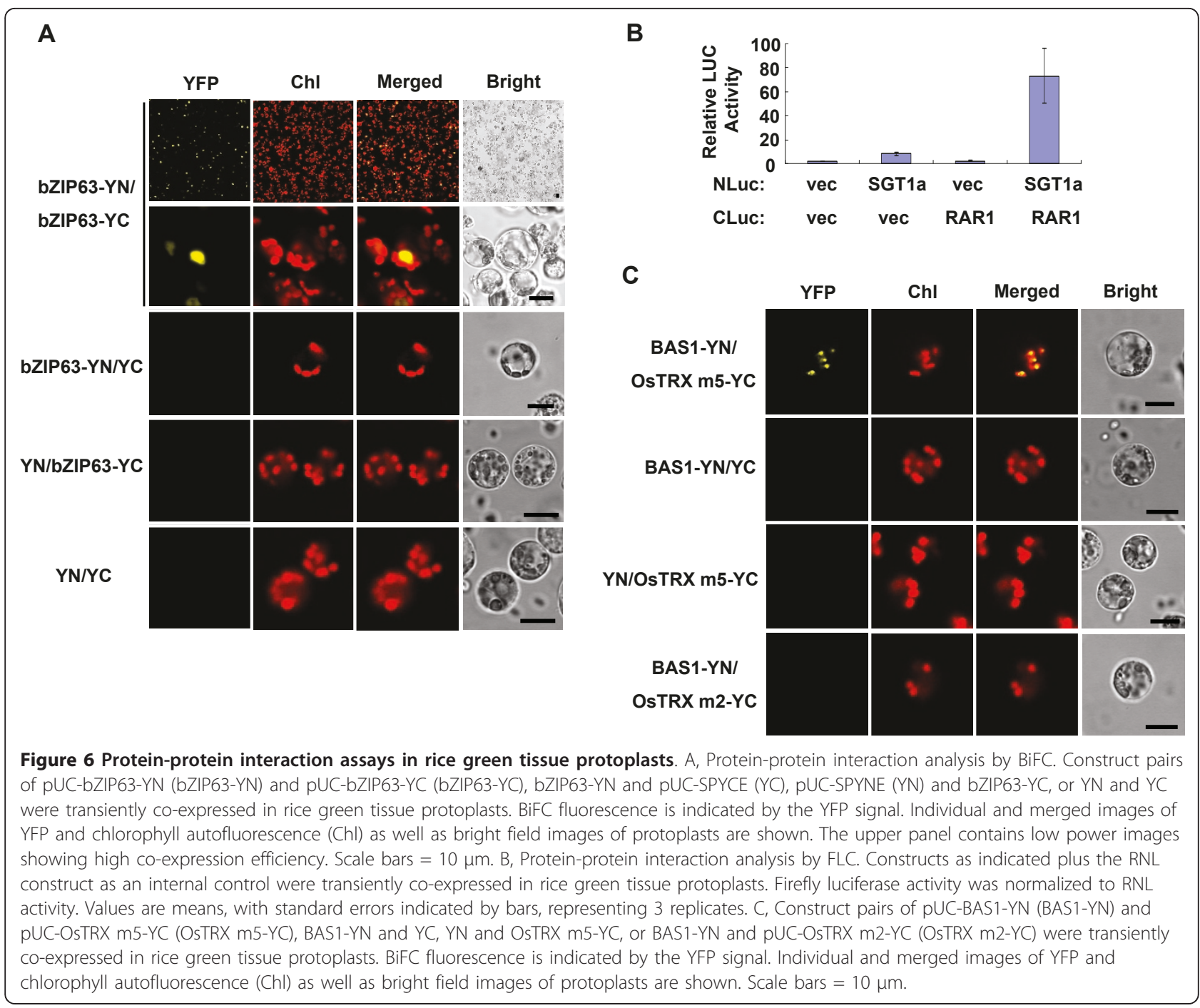

A set of heterologous Arabidopsis organelle markers was also tested for subcellular localization studies in this rice green tissue protoplast system (Additional file 3). The majority of the Arabidopsis organelle markers tested could target to the correct compartments. The YFP or mCherry fluorescence of Arabidopsis plastid marker proteins merged perfectly with the chlorophyll autofluorescence (Figure 4E and 4F), labeling chloroplasts of cells from green tissue. The Arabidopsis peroxisomes were observed as small and round organelles, exhibiting small fluorescent spots in association with the chloroplasts (Figure 4E). The Arabidopsis endoplasmic reticulum (ER) presented as an extensive network throughout the cytoplasm (Figure 4E). The Arabidopsis Golgi marker was observed as small, nearly round spots (Figure 4E). However, a few heterologous Arabidopsis markers showed ambiguous localization or partial mis-localization in the rice system. For example, some Arabidopsis ER markers produced an altered labeling pattern that surrounded the chloroplasts in a half-moon shape; and instead of labeling the plasma membrane (PM), the Arabidopsis PM marker localized to the cytosol and nucleus (Additional file 4).

Furthermore, we used fluorescently-tagged organelle markers to mimic co-localization analysis as co-localization with known organelle markers is often used to determine the location of a protein [2]. The plastid-YFP marker CD3998 and plastid-mCherry marker CD3-1000 were found co-localized in the same chloroplasts (Figure 5, upper panel). Likewise, the co-expressed Golgi-YFP marker CD3966 and plastid-mCherry marker CD3-1000 could easily be detected in the same cells (Figure 5, lower panel).

\section{Detection of protein-protein interactions in rice green tissue protoplasts}

We further applied this method to investigate proteinprotein interactions by bimolecular fluorescence 
complementation (BiFC) [30] and firefly luciferase complementation (FLC) assays [31]. The bZIP transcription factors are known to form homodimers in the nucleus [32]. Co-expression of the bZIP63-c-myc-YFP ${ }^{\mathrm{N}}$ and bZIP63-HA-YFP ${ }^{C}$ fusion proteins in rice green tissue protoplasts produced obvious YFP signals in the nucleus (Figure 6A), consistent with previous results reported in Arabidopsis protoplasts and tobacco leaves [30]. As negative controls, co-expression of pUC-bZIP63-YN and empty pUC-SPYCE vectors, empty pUC-SPYNE and pUC-bZIP63-YC vectors, or two empty vectors pUC-SPYNE and pUC-SPYCE did not produce BiFC fluorescence (Figure 6A). The low power images in Figure 6A (upper panel) again demonstrated that a high co-transfection efficiency could be achieved in the rice green tissue protoplast system.

FLC assays were performed by using the SGT1a-NLuc and CLuc-RAR1 constructs, which carried the $\mathrm{N}$-terminal and C-terminal halves of the luciferase protein, respectively. When co-expressed in cells, these constructs were expected to come together due to the known interaction of SGT1a with RAR1 [31], at the same time reconstituting a functional luciferase enzyme. A renilla luciferase (RNL) vector was co-transfected in all FLC experiments, serving as an internal control, and the firefly luciferase activity was normalized to RNL activity. As negative controls, co-transfections of the SGT1a-NLuc and empty 35S::CLuc vectors, the empty 35S::NLuc and CLuc-RAR1 vectors, or two empty vectors $35 \mathrm{~S}::$ NLuc and $35 \mathrm{~S}::$ CLuc, plus a RNL vector, did not show or exhibited only low background relative luciferase activity (between 2-8 units, Figure 6B). Meanwhile, co-transfection of the SGT1a-NLuc and CLuc-RAR1 constructs resulted in strong relative Luciferase activity (73 units), indicating a specific interaction (Figure 6B).

As a proof of concept, we used the rice green tissue protoplast system to detect whether OsTRX $\mathrm{m} 5$ and BAS1 interacted in vivo, as 2-Cys peroxiredoxin was suggested to be a potential target of thioredoxin OsTRX $\mathrm{m} 5$ [28]. Co-expression of the BAS1-c-myc-YFP ${ }^{\mathrm{N}}$ and OsTRX m5-HA-YFP fusion proteins in rice green tissue protoplasts produced obvious YFP signals in the chloroplasts (Figure 6C), consistent with the subcellular location of BAS1 (Figure 4D). Meanwhile, OsTRX m2 did not interact with BAS1 in our experiment, and cotransfection of pUC-BAS1-YN and empty pUC-SPYCE vectors or empty pUC-SPYNE and pUC-OsTRX m5-YC vectors did not show BiFC fluorescence (negative controls, Figure $6 \mathrm{C}$ ). These results further supported BAS1 as a potential target of thioredoxin OsTRX m5.

\section{Studies of light/chloroplast-related processes in rice green tissue protoplasts}

Rice green tissue protoplasts provide a physiological and versatile cell system to characterize gene functions, which may be potentially used to investigate light/chloroplast-related cellular processes. Thus, we first examined whether the rice green tissue protoplasts were photosynthetically active using an Imaging-PAM chlorophyll fluorometer. The imaging color of the maximum photosystem II quantum yield $\left(\mathrm{F}_{\mathrm{v}} / \mathrm{F}_{\mathrm{m}}\right)$ [33] in etiolated protoplasts was black $\left(\mathrm{F}_{\mathrm{v}} / \mathrm{F}_{\mathrm{m}}=0\right)$, but that in rice green tissue protoplasts was light blue $\left(\mathrm{F}_{\mathrm{v}} / \mathrm{F}_{\mathrm{m}}=0.52\right)$, indicating the rice green tissue protoplast cells were photosynthetically active (Figure 7A and 7B). When rice green tissue protoplasts were treated with low light $(40 \mu \mathrm{mol}$ $\mathrm{m}^{-2} \mathrm{~s}^{-1}$ ) and/or the retrograde plastid signaling inducer norflurazon (NF, $500 \mathrm{nM}$ ), the expressions of photosynthetic genes OsLhcb1 (chlorophyll a/b-binding protein 1), OsLhcp (LHCII type I CAB-2), GADPH (glyceraldehyde-3-phosphate dehydrogenase) and $R b c S$ (nuclearencoded small subunit of ribulose-1,5-bisphosphate carboxylase/oxygenase) were detected by quantitative real-time PCR. The transcript levels of the four genes in rice green tissue protoplasts were decreased by $20-55 \%$ under NF treatment (Figure 8A-D), indicating the rice green tissue protoplasts were sensitive to the retrograde plastid signaling inducer.

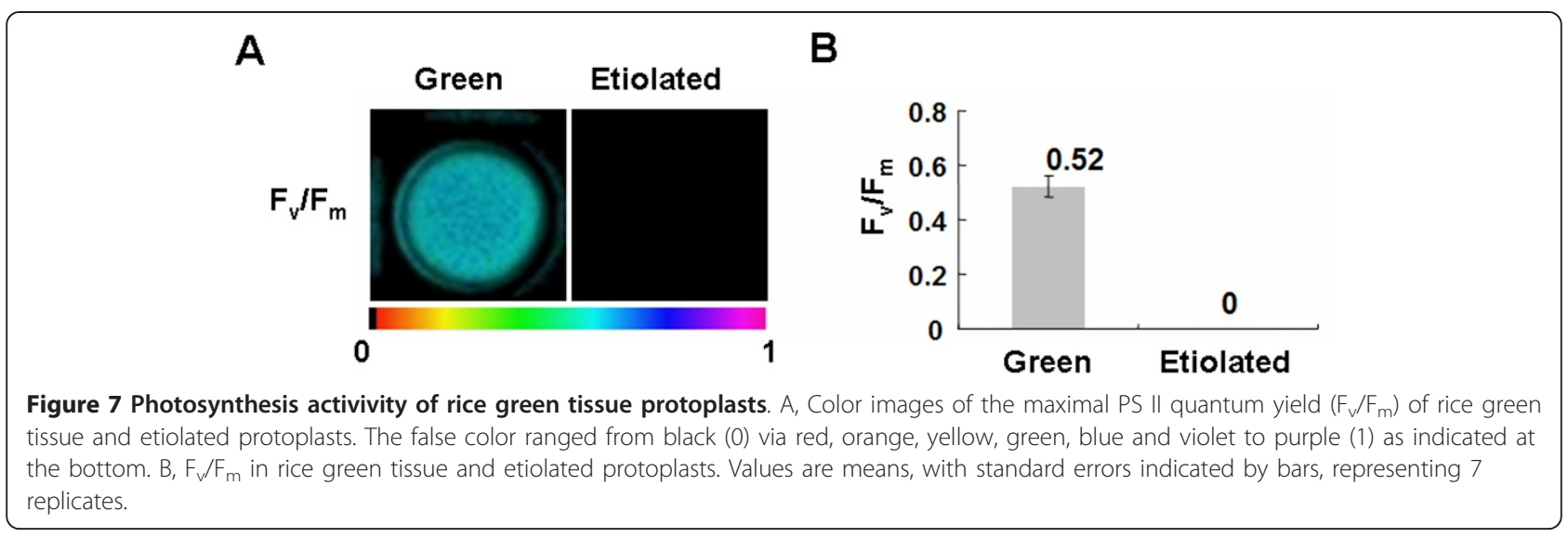


A

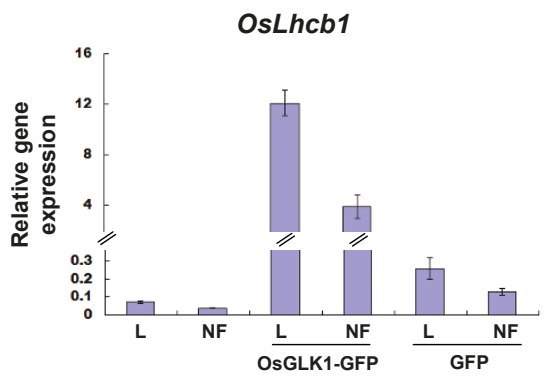

B

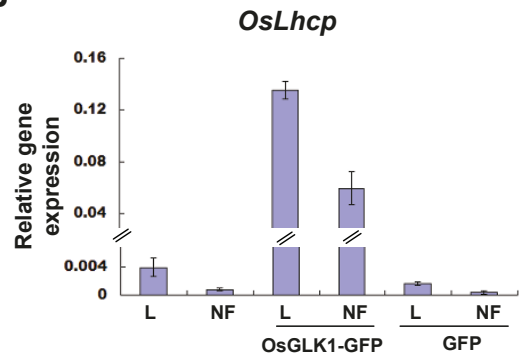

C

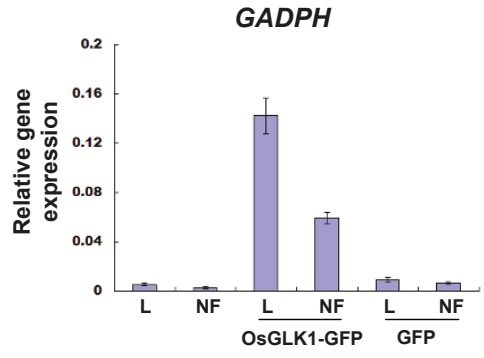

D

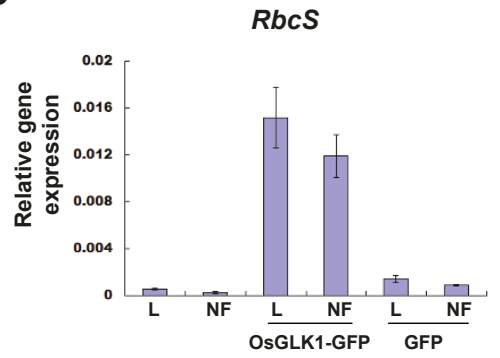

E

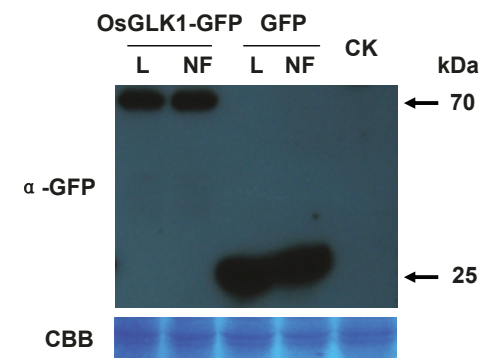

Figure 8 Expression levels of OsGLK1-upregulated genes in rice green tissue protoplasts under light and NF treatments. Protoplasts transfected with/without OsGLK1-GFP or GFP were treated with $40 \mu \mathrm{mol} \mathrm{m}{ }^{-2} \mathrm{~s}^{-1}$ light and/or $500 \mathrm{nM}$ NF for $12 \mathrm{~h}$. A-D, Transcript levels of OsLhcb1, OsLhcp, GADPH and RbcS were detected by quantitative real-time PCR and normalized to that of $\beta$-actin. Values are means, with standard errors indicated by bars, representing 3 independent biological samples, each with 3 technical replicates. E, Detection of transiently expressed OsGLK1GFP (lanes 1-2) and GFP (lanes 3-4) by Western blot. CK was a negative control. The upper panel shows an immunoblot using a monoclonal rabbit anti-GFP antibody. As a loading control, a Coomassie Brilliant Blue (CBB)-stained PVDF membrane is shown in the lower panel. 
The results above suggested these rice protoplasts can be used for investigating light/chloroplast-related cellular processes. To further support this concept, we expressed a light-related transcription factor OsGLK1 combined with light and/or NF treatment in the rice green tissue protoplasts. GLK transcription factors are known to markedly upregulate the transcript levels of photosynthetic genes under light, while the transcript levels of both GLKs and photosynthetic genes are regulated by feedback signals from the plastid [34,35]. In our study, the four photosynthetic genes (OsLhcb1, OsLhcp, GADPH and $R b c S$ ) were upregulated by 30-168 fold in protoplasts expressing OsGLK1-GFP compared to those without OsGLK1-GFP expression, while NF treatment decreased the levels of these up-regulated genes by 30-75\% (Figure 8A-D). Similarly, downward trends of transcript levels of OsLhcb1, OsLhcp, GADPH and RbcS (23-72\%) were seen in the protoplasts expressing GFP with NF treatment compared with those expressing GFP only without NF treatment (Figure 8A-D). As a control, expression of the proteins OsGLK1-GFP (around $70 \mathrm{kDa}$ ) and GFP (27 kDa) were evaluated by Western blot using a monoclonal rabbit antibody to GFP, which clearly showed similar protein expressions in light and/or NF treatment (Figure 8E).

\section{Discussion}

Although the rice green tissue protoplast system has been widely used in many applications, it does have a few limitations. For example, protoplasts cannot be used to characterize proteins localized to the cell wall or to study direct interactions between cells, since by definition individual protoplasts lack a cell wall and connections to other cells. However, as the results are shown above and discussed below, rice protoplasts from green tissue confer many advantages for plant biological studies. Here, we used rice green tissue to establish a physiological and versatile protoplast system for transient gene expression. We simplified the protoplast isolation protocol and systematically applied the rice green tissue protoplasts in protein immunoblot, localization and protein-protein interaction assays. Finally, we validated the use of the rice green tissue protoplasts in studies of light/chloroplast-related processes.

\section{A rapid and highly efficient transient gene expression system in rice green tissue protoplasts}

The rice protoplast isolation method was simplified by removing use of unnecessary chemicals and a vacuum device from the protocol. The green stem and sheath of young rice green seedlings cultured at $26^{\circ} \mathrm{C}$ on $1 / 2 \mathrm{MS}$ medium with a photoperiod of $12 \mathrm{~h}$ light (about $150 \mu \mathrm{mol}$ $\left.\mathrm{m}^{-2} \mathrm{~s}^{-1}\right) / 12 \mathrm{~h}$ dark cycle were used as the source material. A short plasmolysis treatment before enzymatic digestion was used for osmoticum equilibrium, in order to maintain protoplast viability and reduce spontaneous protoplast fusion [36]. We found that fresh and tender rice seedlings were key to isolating protoplasts that could be transfected at high efficiencies, with 7 to 10-day-old seedlings being the most suitable for this purpose. The transfection efficiencies were variable in protoplasts from 11 to 14-day-old seedlings and declined sharply with those from seedlings older than 14 days. In contrast, other reported methods utilize 2-week-old or 2-month-old rice green tissue, antibiotics, toxic chemicals or vacuum $[24,25]$.

Following PEG-mediated transfection [8], we achieved a maximum transfection efficiency of $75 \%$ using protoplasts isolated from rice green tissue (Figure $2 \mathrm{C}$ and $3 \mathrm{~A})$, matching that of the most effective transient gene expression system in etiolated rice protoplasts (70\%) [24,25]. Maximum efficiencies of 45-66\% were obtained with a large sized (13 kb) binary plasmid (Figure 3 ). Moreover, good transfection efficiencies were also obtained when two $13 \mathrm{~kb}$ plasmids (Figure 5) or three constructs (Figure 6B) were co-transfected. These results demonstrated that transfection using our rice green tissue protoplast system is a simple, highly efficient and rapid process, suitable for co-expressing multiple constructs of a wide range of sizes (4.5-13 kb).

\section{Suitability of rice green tissue protoplasts for analysis by protein immunoblotting, subcellular localization and protein-protein interactions assays}

Transiently expressed proteins are often used in immunoblotting and activity assays [37]. In our study, the amount of protein expressed from a small scale transfection $(5 \mu \mathrm{g}$ plasmid per $2 \times 10^{5}$ rice green tissue protoplast cells) was sufficient for protein assays (Figure 2D and $8 \mathrm{E}$ ). As the transfection efficiency was not significantly different between 5-15 $\mu \mathrm{g}$ of plasmid DNA (data not shown), it stands to reason that probably using less DNA in the lower limit of this range with a higher number of protoplasts in a single transfection would increase total levels of expressed proteins to suit particular experimental needs.

Transient expression is also commonly applied in fluorescent-based assays, especially of target proteins fused to fluorescent tags for subcellular localization analysis. In our study, all rice plastid [28,29] and mitochondrion [27] fusion proteins targeted to their corresponding compartments in the rice green tissue protoplasts as expected (Figure 4A-D). Although the Arabidopsis plastids, peroxisomes, ER and Golgi markers [38] could largely target to their corresponding compartments in rice green tissue protoplast system as well (Figure 4E and 4F), we observed partial mis-localization of a few heterologous Arabidopsis markers in this system (Additional file 4). These findings suggested that it is always better to use a homologus system to study protein localization since a heterologous system may result in mis-targeting [2]. 
Proteins typically interact dynamically and form functional complexes to participate in signaling pathways and regulatory networks $[39,40]$. Thus, the ability to identify, examine and visualize protein-protein interactions in living cells is highly valuable. We were able to successfully apply the rice green tissue protoplast system to studying protein-protein interactions by using BiFC (Figure 6A and 6C), one of the most powerful tools for such analysis in situ using living cells $[30,41]$. The high co-transfection efficiency in rice green tissue protoplasts would no doubt facilitate the gathering of fluorescence data from large numbers of cells when performing BiFC analyses.

We also successfully used the rice green tissue protoplasts to perform the FLC assay, which was recently developed to quantitatively measure dynamic changes in protein-protein interactions in living cells [31,42]. The SGT1a and RAR1 interaction [31] was demonstrated to be 9-35 fold higher than the signal obtained with negative controls (Figure 6B), indicating the rice green tissue protoplasts can be used for dynamic protein interaction studies.

As a proof of concept, we also investigated subcellular localization and protein-protein interactions of OsTRX $\mathrm{m} 2$, OsTRX $\mathrm{m} 5$ and BAS1, which all targeted to the chloroplasts as predicted when expressed in the rice green tissue protoplast system, although with different patterns: OsTRX m2 as small fluorescent spots, OsTRX m5 filling the chloroplasts [28], and BAS1 as one large fluorescent spot per chloroplast (Figure 4B-D). These different localization patterns suggested specific localization of each protein inside chloroplasts. Moreover, we confirmed the interaction of BAS1 with OsTRX $\mathrm{m} 5$ in vivo (Figure 6C), further supporting BAS1 is a potential target of thioredoxin OsTRX m5 as previously suggested [28]

\section{Potential of rice green tissue protoplasts for studies of chloroplast or light-related cellular processes}

As mentioned above, green protoplasts provide a suitable system for the study of many physiological and biochemical processes of plant cells [20]. The transcriptional activator Dof1 involved in light-regulated gene expression is activated in green protoplasts but not in etiolated protoplasts [23], suggesting that green protoplasts are more suitable in light/chloroplast-related studies as has been demonstrated in tobacco leaf and maize $[21,22]$. However, no such studies have been reported using rice protoplasts, currently obtained mainly from suspension cultured cells and etiolated cells $[18,19,24,25]$ that are grown in the dark and lack light-dependent proteins or structures [43].

In this work, we demonstrated that the rice green tissue protoplasts were photosynthetically active (Figure 7) and sensitive to the retrograde plastid signaling inducer NF (Figure 8A-D), suggesting their potential to be used in light/chloroplast-related studies. The feasibility of such studies was further demonstrated when we showed that transient expression of a light-related transcription factor OsGLK1 markedly upregulated the transcript levels of various endogenous photosynthetic genes (OsLhcb1, OsLhcp, GADPH and $R b c S$ ), which were reduced to some extent by treatment with the retrograde plastid signaling inducer NF in rice green tissue protoplasts (Figure 8) $[34,35]$. It is conceivable that such experiments can be extended in future studies using the rice green tissue protoplast system for high-throughput gene analysis as has been demonstrated with various other plant protoplast systems [1].

\section{Conclusions}

In conclusion, we show here that a physiological and versatile protoplast system, using fresh and tender rice green tissue, allowed for rapid and highly efficient DNA transfection for analysis by protein immunoblot, localization and protein-protein interaction assays. This system was successfully used for the simultaneous expression of multiple constructs and plasmids of a wide range of sizes. Notably, the protoplasts from rice green tissue, unlike those from etiolated or cultured suspension cells currently used, were demonstrated to be a useful system for studies of light/ chloroplast-related processes.

\section{Methods}

\section{Protoplast isolation}

Dehulled seeds of rice (Oryza sativa L.) cultivar Nipponbare were sterilized with $75 \%$ ethanol for $1 \mathrm{~min}$. These seeds were further sterilized with $2.5 \%$ sodium hypochlorite for $20 \mathrm{~min}$, washed at least five times with sterile water and then incubated on $1 / 2 \mathrm{MS}$ medium with a photoperiod of $12 \mathrm{~h}$ light (about $150 \mu \mathrm{mol} \mathrm{m} \mathrm{s}^{-2}$ ) and $12 \mathrm{~h}$ dark at $26^{\circ} \mathrm{C}$ for 7-10 days. Green tissues from the stem and sheath of 40-60 rice seedlings were used. A bundle of rice plants (about 30 seedlings) were cut together into approximately $0.5 \mathrm{~mm}$ strips with propulsive force using sharp razors. The strips were immediately transferred into $0.6 \mathrm{M}$ mannitol for $10 \mathrm{~min}$ in the dark. After discarding the mannitol, the strips were incubated in an enzyme solution (1.5\% Cellulase RS, 0.75\% Macerozyme R-10, 0.6 M mannitol, $10 \mathrm{mM} \mathrm{MES} \mathrm{at} \mathrm{pH} \mathrm{5.7,} 10 \mathrm{mM} \mathrm{CaCl}_{2}$ and $0.1 \%$ BSA) for 4-5 h in the dark with gentle shaking (60-80 $\mathrm{rpm})$. After the enzymatic digestion, an equal volume of W5 solution (154 mM NaCl, $125 \mathrm{mM} \mathrm{CaCl}_{2}, 5 \mathrm{mM} \mathrm{KCl}$ and $2 \mathrm{mM}$ MES at pH 5.7) was added, followed by vigorous shaking by hand for $10 \mathrm{sec}$. Protoplasts were released by filtering through $40 \mu \mathrm{m}$ nylon meshes into round bottom tubes with 3-5 washes of the strips using W5 solution. The pellets were collected by centrifugation at $1,500 \mathrm{rpm}$ for 3 min with a swinging bucket. After washing once with W5 solution, the pellets were then resuspended in MMG solution (0.4 M mannitol, $15 \mathrm{mM} \mathrm{MgCl}_{2}$ and $4 \mathrm{mM} \mathrm{MES}$ at $\mathrm{pH} 5.7)$ at a concentration of $2 \times 10^{6}$ cells $\mathrm{mL}^{-1}$, 
determined by using a hematocytometer. The viability of protoplasts was determined by the FDA staining method as described [44]. All manipulations above were performed at room temperature.

For isolating protoplasts from etiolated rice seedlings, the sterilized seeds were germinated under light for 3 days, and then moved to the dark for another 4-7 days. The isolation procedure was the same as that for isolation of green tissue protoplasts described above.

\section{Plasmids}

The recombinant plasmids used in this study are listed in Additional file 3. Plasmids pUC-GFP and pUC-YFP were derived from pUC 19 [45]. OsTRX $m 2$ (Os04g0530600), OsTRX m5 (Os12g0188700), BAS1 (Os02g0537700) with introduced XbaI and XhoI sites, and OsGLK1 (AK098909) with introduced $X b a \mathrm{I}$ and SpeI sites were cloned from rice cDNA without the stop codon and inserted into pUCGFP. The N-terminal coding region of OsRpl6-2 (Os08g0484301, 1-52 amino acids) was cloned from rice cDNA with introduced $X b a \mathrm{I}$ and $\mathrm{XhoI}$ sites and inserted into pUC-YFP. The primer sequences with corresponding enzyme sites underlined are as follows: OsTRX $m 2,5$, TCTAGACGTCCCCGTCTCTCGATCG 3' and 5' CTCG AGCCTCTCGACAAATTTCTC 3'; OsTRX m5, 5’ GCT TCTAGAATGGCGTTGGAGACGT 3' and 5' CATCTCGAGGCTGCTGACGTACTTG 3'; BAS1, 5' T्TCAGAATGGCCGCCTGCTGCTCCT 3' and 5' CTCGAG GATGGCCGCGAAGTACTCC 3'; OsGLK1, 5' TCTAGAGAGATGCTTGCCGTGTCGC 3' and 5' ACTAGTTCCA CACGCTGGAGGAACG 3'; OsRpl6-2, 5' GCTCTAGAATGGAAGCCAAGTTTTTC 3' and 5' ATGCTCGAGGGGTTTAAAGCAGAAGAC 3'. Plasmids $\overline{\text { pUC- }}$ SPYNE and pUC-SPYCE were described previously [30].

Plasmids pUC-bZIP63-YN and pUC-bZIP63-YC were made by cloning the bZIP63 fragment without the stop codon from Arabidopsis cDNA and inserting into the pUC-SPYNE and pUC-SPYCE multiple cloning sites (MCS) with BamHI and XhoI [30]. Plasmids pUCBAS1-YN, pUC-OsTRX m2-YC and pUC-OsTRX m5$\mathrm{YC}$ were constructed by transferring their coding sequences into pUC-SPYNE and PUC-SPYCE MCS at

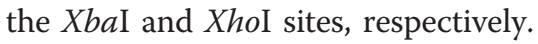

Plasmid DNA was prepared by standard kits, such as Omega and TIANGEN (Beijing) according to the manufacturer's instructions with some modifications. Two or more columns, each for 5-8 mL bacterial cells cultured for 12-16 h, were used for plasmid DNA purification. After the precipitated DNA was bound to the columns, the deproteinization buffer was added to remove unwanted metabolites and repeated twice. The DNA was then washed twice with wash buffer. An appropriate amount of sterilized distilled water, generally $50 \mu \mathrm{L}$ per two columns, was added to the center of one column to elute the DNA.
The DNA solution was collected by centrifugation for $1 \mathrm{~min}$ and then added to another column. The combined plasmid DNA from all columns was collected in one Eppendorf tube. The DNA concentration and quality were determined using a DU ${ }^{\mathbb{R}} 730$ Beckman Nucleic Acid/Protein Analyzer. The DNA purified from two columns usually resulted in a concentration of $1-2 \mu \mathrm{g} \mu \mathrm{L}^{-1}$. All plasmids were stored at $-20^{\circ} \mathrm{C}$ before use.

\section{Protoplast transfection}

PEG-mediated transfections were carried out as described [8]. Briefly, for each sample 5-10 $\mu \mathrm{g}$ of plasmid DNA were mixed with $100 \mu \mathrm{L}$ protoplasts (about $2 \times 10^{5}$ cells). For BiFC or other co-expression assays, the total plasmid DNA was between $10 \mu \mathrm{g}$ and $15 \mu \mathrm{g}$. $110 \mu \mathrm{l}$ freshly prepared PEG solution [40\% (W/V) PEG 4000; Fluka, 0.2 M mannitol and $0.1 \mathrm{M} \mathrm{CaCl}_{2}$ ] were added, and the mixture was incubated at room temperature for 10-20 $\mathrm{min}$ in the dark. After incubation, $440 \mu \mathrm{L}$ W5 solution were added slowly. The resulting solution was mixed well by gently inverting the tube, and the protoplasts were pelleted by centrifugation at $1,500 \mathrm{rpm}$ for $3 \mathrm{~min}$. The protoplasts were resuspended gently in $1 \mathrm{~mL}$ WI solution $(0.5 \mathrm{M}$ mannitol, $20 \mathrm{mM} \mathrm{KCl}$ and $4 \mathrm{mM} \mathrm{MES}$ at pH 5.7). Finally, the protoplasts were transferred into multi-well plates and cultured under light or dark at room temperature for 6$16 \mathrm{~h}$. The amount of DNA, protoplasts and other solutions used in this transfection sysem could be scaled up or down based on experimental purposes.

\section{Confocal laser scanning microscopy}

Protoplasts were observed using a confocal laser scanning microscope (Leica TCS 5 SP5 AOBS) and visualized by a Leica Microsystem LAS AF. GFP, YFP and mCherry were excitated at $488 \mathrm{~nm}, 514 \mathrm{~nm}$ and $561 \mathrm{~nm}$ wavelengths, respectively. The emission filters were $500-530 \mathrm{~nm}$ for GFP, 530-560 nm for YFP and 580-620 nm for mCherry. Chlorophyll autofluorescence was monitored using either $488 \mathrm{~nm}$ or $514 \mathrm{~nm}$ excitation wavelengths, and 650-750 $\mathrm{nm}$ detection windows. All fluorescence experiments were repeated independently at least three times.

\section{Total protein extraction, Western blot and Luciferase activity measurement}

Protoplasts were harvested by centrifugation at 1,500 $\mathrm{rpm}$ for $3 \mathrm{~min}$. Total protein was extracted with protein extraction buffer $(50 \mathrm{mM}$ Tris- $\mathrm{HCl}$ at $\mathrm{pH} 7.5,150 \mathrm{mM}$ $\mathrm{NaCl}, 5 \mathrm{mM}$ EDTA, $0.2 \% \mathrm{NP}-40,0.1 \%$ Triton X-100 and Complete protease inhibitor cocktail, Roche), usually $200-300 \mu \mathrm{L}$ for $1 \mathrm{~mL}$ protoplasts (approximately $2 \times 10^{6}$ cells). The extracts were then centrifuged at $16,000 \mathrm{rpm}$ for $15 \mathrm{~min}$ at $4^{\circ} \mathrm{C}$, and the supernatants were collected for Western blot analysis. About $20 \mu \mathrm{g}$ of total protein per sample, determined by the Bradford 
Assay (BioRad), were analyzed by SDS-PAGE. Western analysis was performed with a monoclonal mouse antic-myc (Roche) or monoclonal rabbit anti-GFP (Abmart) primary antibody according to standard protocols [46]. Firefly luciferase and renilla luciferase activities were measured using the Dual-Luciferase ${ }^{\circledR}$ Reporter Assay System (Promega). RNL [47] was co-transfected in all FLC experiments, serving as an internal control, and firefly luciferase activity was normalized to RNL activity.

\section{Chlorophyll fluorescence measurements}

The photosynthetic properties of rice protoplasts were measured in 96-well white polystyrene plates (Corning) using an IMAGING-PAM chlorophyll fluorometer (MAXI Version; Walz, Efeltrich, Germany) with imaging areas up to $10 \mathrm{~cm} \times 13 \mathrm{~cm}$. Areas of interest (AOI, diameter $0.5 \mathrm{~cm}$ ) were selected randomly to record data. Images of the chlorophyll fluorescence parameters were taken under saturation pulse mode, and the concrete features were as follows: dark adaptation was $10 \mathrm{~min}$ for each protoplast sample; measured light intensity was $0.5 \mu \mathrm{mol} \mathrm{m}{ }^{-2} \mathrm{~s}^{-1}$; saturation pulse light was $2,700 \mu \mathrm{mol} \mathrm{m}{ }^{-2} \mathrm{~s}^{-1}$ (duration $0.8 \mathrm{~s}$; interval $20 \mathrm{~s}$ ) and actinic light intensity was $35 \mu \mathrm{mol}$ $\mathrm{m}^{-2} \mathrm{~s}^{-1}$. Fluorescence data and the corresponding images were recorded simultaneously.

\section{RNA extraction and Quantitative real-time PCR analysis}

Total RNA of rice protoplasts was extracted using the Omega Plant RNA kit according to the manufacturer's instructions. cDNA was made using the PrimeScript RT reagent Kit with gDNA eraser (Taraka) with $2 \mu \mathrm{g}$ of total RNA as the template. Quantitative real-time PCR was performed with a Bio-Rad IQ5 system using SYBR to monitor double-stranded DNA products. The gene-specific primers were as follows: OsLhcb1 (Os09g0346500), 5' GGAAGATGGGTTTAGTGCG 3' and 5' GCTAATCAGAATAACACCACGG 3'; OsLhcp (Os01g0600900), 5' TACGAGTATTGGAGAGAGG 3' and 5' TAAGTAGCACGCAGGATT 3'; GADPH (Os03g0129300), 5' GT GGCCAACATTATCAGCAA 3' and 5' GGTCATGGT TCCCTTTACGA 3'; RbcS (Os12g0292400), 5' CCCGGATACTATGACGGTAGG 3' and 5' AACGAAGGCATCAGGGTATG 3'; $\beta$-actin (internal control), 5' CCTG ACGGAGCGTGGTTAC 3' and 5' CCAGGGCGATGTAGGAAAGC 3'.

\section{Additional material}

Additional file 1: Eight-day-old rice seedlings. Sterilized rice seeds were germinated and cultured on $1 / 2 \mathrm{MS}$ medium with a photoperiod of $12 \mathrm{~h}$ light (about $150 \mu \mathrm{mol} \mathrm{m} \mathrm{s}^{-1}$ ) and $12 \mathrm{~h}$ dark at $26^{\circ} \mathrm{C}$. Scale bar $=1 \mathrm{~cm}$.

Additional file 2: Viability of rice green tissue protoplasts. Rice green tissue protoplasts were stained with $0.01 \%$ fluorescein diacetate (FDA). The viable cells were visualized under a fluorescent microscope indicated by green fluorescence. A bright field image of protoplasts is also shown. Scale bar $=50 \mu \mathrm{m}$.

Additional file 3: List of recombinant plasmids used in this study. The information of recombinant plasmids used in this study is listed. It includes transfection controls, BiFC and FLC controls, and rice and Arabidopsis organelle markers.

Additional file 4: Mis-localization of Arabidopsis organelle markers in heterologous rice expression system. Transient expression of Arabidopsis organelle markers in rice green tissue protoplasts showed partial ambiguous localizations. CD3-958 formed rings around the chloroplasts that did not coincide with the endoplasmic reticulum (ER). CD3-1006 did not label the plasma membrane (PM) as expected but instead was found in the cytosol and nucleus. Individual and merged images of YFP and chlorophyll autofluorescence (Chl) as well as bright field images of protoplasts are shown. Scale bars $=10 \mu \mathrm{m}$.

\section{Acknowledgements}

We gratefully acknowledge the Arabidopsis Biological Resource Center (Ohio State University, Columbus, OH) for providing the plasmids of Arabidopsis organelle markers; Jörg Kudla (University of Münster, Münster, Germany) and Weihua Wu (China Agricultural University, Beijing, China) for gifting plasmids pUC-SPYNE and pUC-SPYCE; Jianmin Zhou (National Institute of Biological Sciences, Beijing, China) for gifting plasmids SGT1a-NLuc, CLuc-RAR1, 35S:: CLuC and 35S::CLuc; Jianfeng Li (Harvard Medical School, Boston, MA) for technical assistance in the isolation and transfection of protoplasts. This research was supported by grants from the National Natural Science Foundation of China (No. 30800600 and No. 30970237), the Natural Science Foundation of Guangdong Province, P. R. China (No. 8151027501000016 ) and the Fundamental Research Funds for the Central Universities (10lgpy34).

\section{Author details}

${ }^{1}$ State Key Laboratory of Biocontrol, School of Life Sciences, Sun Yat-sen University, Guangzhou 510275, P. R. China. ${ }^{2}$ Key Laboratory of Gene Engineering of Ministry of Education, School of Life Sciences, Sun Yat-sen University, Guangzhou 510275, P. R. China. ${ }^{3}$ Guangdong Key Laboratory of Plant Resources, School of Life Sciences, Sun Yat-sen University, Guangzhou 510275, P. R. China.

\section{Authors' contributions}

YZ, JS and HW designed the study. YZ and JS optimized the protoplast system and drafted the manuscript. SD performed the FDA staining and chlorophyll fluorescence measurements. YA, JL and PW conducted the statistical analysis and FLC assays. JD and YL performed the Western blot and quantitative real-time PCR assays. BL and DF prepared materials, including rice seedlings and vectors, and provided assistance in the revision of the manuscript. HW and JW supervised the study and critically revised the manuscript. All authors read and approved the final manuscript.

\section{Competing interests}

The authors declare that they have no competing interests.

Received: 22 August 2011 Accepted: 30 September 2011 Published: 30 September 2011

\section{References}

1. De Sutter V, Vanderhaeghen R, Tilleman S, Lammertyn F, Vanhoutte I, Karimi M, Inzé D, Goossens A, Hilson P: Exploration of jasmonate signalling via automated and standardized transient expression assays in tobacco cells. Plant J 2005, 44(6):1065-1076.

2. Marion J, Bach L, Bellec Y, Meyer C, Gissot L, Faure JD: Systematic analysis of protein subcellular localization and interaction using high-throughput transient transformation of Arabidopsis seedlings. Plant J 2008, 56(1):169-179.

3. Sheen J: Signal transduction in maize and Arabidopsis mesophyll protoplasts. Plant Physiol 2001, 127(4):1466-1475.

4. Fischer R, Hain R: Tobacco protoplast transformation and use for functional analysis of newly isolated genes and gene constructs. Methods Cell Biol 1995, 50:401-410. 
5. Zang A, Xu X, Neill S, Cai W: Overexpression of OsRAN2 in rice and Arabidopsis renders transgenic plants hypersensitive to salinity and osmotic stress. J Exp Bot 2010, 61(3):777-789.

6. Lam SK, Siu CL, Hillmer S, Jang S, An G, Robinson DG, Jiang L: Rice SCAMP1 defines clathrin-coated, trans-golgi-located tubular-vesicular structures as an early endosome in tobacco BY-2 cells. Plant Cell 2007 19(1):296-319.

7. Kitajima A, Asatsuma S, Okada H, Hamada Y, Kaneko K, Nanjo Y, Kawagoe Y, Toyooka K, Matsuoka K, Takeuchi M, et al: The Rice a-Amylase Glycoprotein Is Targeted from the Golgi Apparatus through the Secretory Pathway to the Plastids. Plant Cell 2009, 21(9):2844-2858.

8. Yoo SD, Cho YH, Sheen J: Arabidopsis mesophyll protoplasts: a versatile cell system for transient gene expression analysis. Nat Protoc 2007, 2(7):1565-1572.

9. Ueki S, Lacroix B, Krichevsky A, Lazarowitz SG, Citovsky V: Functional transient genetic transformation of Arabidopsis leaves by biolistic bombardment. Nat Protoc 2009, 4(1):71-77.

10. Manavella PA, Chan RL: Transient transformation of sunflower leaf discs via an Agrobacterium-mediated method: applications for gene expression and silencing studies. Nat Protoc 2009, 4(11):1699-1707.

11. Cantrell RP, Reeves TG: The rice genome. The cereal of the world's poor takes center stage. Science 2002, 296(5565):53..

12. Bruce WB, Christensen AH, Klein T, Fromm M, Quail PH: Photoregulation of a phytochrome gene promoter from oat transferred into rice by particle bombardment. Proc Natl Acad Sci USA 1989, 86(24):9692-9696.

13. Chavez-Barcenas AT, Valdez-Alarcon JJ, Martinez-Trujillo M, Chen L, Xoconostle-Cazares B, Lucas WJ, Herrera-Estrella L: Tissue-specific and developmental pattern of expression of the rice sps1 gene. Plant Physiol 2000, 124(2):641-654

14. Dekeyser RA, Claes B, Rycke RMUD, Habets ME, Montagu MCV, Caplan AB: Transient Gene Expression in Intact and Organized Rice Tissues. The Plant Cell 1990, 2(7):591-602.

15. Dong J, Kharb P, Teng W, Hall TC: Characterization of rice transformed via an Agrobacterium-mediated inflorescence approach. Mol Breed 2001, 7(3):187-194.

16. Li JF, Park E, von Arnim AG, Nebenfuhr A: The FAST technique: a simplified Agrobacterium-based transformation method for transient gene expression analysis in seedlings of Arabidopsis and other plant species. Plant Methods 2009, 5:6.

17. Liu CN, Li XQ, Gelvin SB: Multiple copies of virG enhance the transient transformation of celery, carrot and rice tissues by Agrobacterium tumefaciens. Plant Mol Biol 1992, 20(6):1071-1087.

18. Shimamoto $K$, Terada $R$, Izawa $T$, Fujimoto $H$ : Fertile transgenic rice plants regenerated from transformed protoplasts. Nature 1989, 338(6212):274-276.

19. Hayashimoto A, Li Z, Murai N: A polyethylene glycol-mediated protoplast transformation system for production of fertile transgenic rice plants. Plant Physiol 1990, 93(3):857-863.

20. Morris P, Thain JF: Comparative Studies of Leaf Tissue and Isolated Mesophyll Protoplasts. J Exp Bot 1980, 31(1):97-104.

21. Augustynowicz J, Lekka M, Burda K, Gabryś H: Correlation between chloroplast motility and elastic properties of tobacco mesophyll protoplasts. Acta Physiol Plant 2001, 23(3):291-302.

22. Augustynowicz J, Krzeszowiec W, Gabrys H: Acquisition of plastid movement responsiveness to light during mesophyll cell differentiation. Int J Dev Biol 2009, 53(1):121-127.

23. Yanagisawa $S$, Sheen J: Involvement of maize Dof zinc finger proteins in tissue-specific and light-regulated gene expression. Plant Cell 1998, 10(1):75-89.

24. Chen S, Tao L, Zeng L, Vega-Sanchez ME, Umemura K, Wang GL: A highly efficient transient protoplast system for analyzing defence gene expression and protein-protein interactions in rice. Mol Plant Pathol 2006, 7(5):417-427

25. Bart R, Chern M, Park C-J, Bartley L, Ronald P: A novel system for gene silencing using siRNAs in rice leaf and stem-derived protoplasts. Plant Methods 2006, 2(1):13.

26. Park CJ, Bart R, Chern M, Canlas PE, Bai W, Ronald PC: Overexpression of the endoplasmic reticulum chaperone BiP3 regulates $\mathrm{XA21-mediated}$ innate immunity in rice. PLoS One 2010, 5(2):e9262.

27. Kubo N, Fujimoto M, Arimura S, Hirai M, Tsutsumi N: Transfer of rice mitochondrial ribosomal protein L6 gene to the nucleus: acquisition of the $5^{\prime}$-untranslated region via a transposable element. BMC Evol Biol 2008, 8:314.

28. Chi YH, Moon JC, Park JH, Kim HS, Zulfugarov IS, Fanata WI, Jang HH, Lee JR, Lee YM, Kim ST, et al: Abnormal chloroplast development and growth inhibition in rice thioredoxin $\mathrm{m}$ knock-down plants. Plant Physiol 2008, 148(2):808-817

29. Baier M, Dietz K-J: The plant 2-Cys peroxiredoxin BAS1 is a nuclearencoded chloroplast protein: its expressional regulation, phylogenetic origin, and implications for its specific physiological function in plants. Plant J 1997, 12(1):179-190.

30. Walter M, Chaban C, Schutze K, Batistic O, Weckermann K, Nake C, Blazevic D, Grefen C, Schumacher K, Oecking C, et al: Visualization of protein interactions in living plant cells using bimolecular fluorescence complementation. Plant J 2004, 40(3):428-438.

31. Chen H, Zou Y, Shang Y, Lin H, Wang Y, Cai R, Tang X, Zhou JM: Firefly luciferase complementation imaging assay for protein-protein interactions in plants. Plant Physiol 2008, 146(2):368-376.

32. Siberil Y, Doireau P, Gantet P: Plant bZIP G-box binding factors. Modular structure and activation mechanisms. Eur J Biochem 2001, 268(22):5655-5666.

33. Maxwell K, Johnson GN: Chlorophyll fluorescence-a practical guide. J Exp Bot 2000, 51(345):659-668.

34. Waters MT, Wang P, Korkaric M, Capper RG, Saunders NJ, Langdale JA: GLK Transcription Factors Coordinate Expression of the Photosynthetic Apparatus in Arabidopsis. Plant Cell 2009, 21(4):1109-1128.

35. Nakamura H, Muramatsu M, Hakata M, Ueno O, Nagamura Y, Hirochika H, Takano M, Ichikawa H: Ectopic Overexpression of The Transcription Factor OsGLK1 Induces Chloroplast Development in Non-Green Rice Cells. Plant Cell Physiol 2009, 50(11):1933-1949.

36. Davey MR, Anthony P: Plant Cell Culture: Essential Methods A John Wiley \& Sons, Ltd., Publication; 2001.

37. Asai T, Tena G, Plotnikova J, Willmann MR, Chiu WL, Gomez-Gomez L, Boller T, Ausubel FM, Sheen J: MAP kinase signalling cascade in Arabidopsis innate immunity. Nature 2002, 415(6875):977-983.

38. Nelson BK, Cai X, Nebenfuhr A: A multicolored set of in vivo organelle markers for co-localization studies in Arabidopsis and other plants. Plant J 2007, 51(6):1126-1136.

39. Alberts B: The Cell as a Collection of Protein Machines: Preparing the Next Generation of Molecular Biologists. Cell 1998, 92(3):291-294.

40. Pawson T, Nash P: Assembly of Cell Regulatory Systems Through Protein Interaction Domains. Science 2003, 300(5618):445-452.

41. Lalonde S, Ehrhardt DW, Loque D, Chen J, Rhee SY, Frommer WB: Molecular and cellular approaches for the detection of protein-protein interactions: latest techniques and current limitations. Plant J 2008, 53(4):610-635.

42. Luker KE, Smith MCP, Luker GD, Gammon ST, Piwnica-Worms H, PiwnicaWorms D: Kinetics of regulated protein-protein interactions revealed with firefly luciferase complementation imaging in cells and living animals. Proc Natl Acad Sci USA 2004, 101(33):12288-12293.

43. Waters MT, Langdale JA: The making of a chloroplast. EMBO J 2009, 28(19):2861-2873.

44. Larkin PJ: Purification and viability determinations of plant protoplasts. Planta 1976, 128(3):213-216.

45. Yanisch-Perron C, Vieira J, Messing J: Improved M13 phage cloning vectors and host strains: nucleotide sequences of the $\mathrm{M} 13 \mathrm{mpl} 8$ and pUC19 vectors. Gene 1985, 33(1):103-119.

46. Sambrook J, Russell DW: Molecular Cloning: A Laboratory Manual. 3 edition. Cold Spring Harbor Laboratory Press; 2001

47. Huq E, Al-Sady B, Hudson M, Kim C, Apel K, Quail PH: PHYTOCHROMEINTERACTING FACTOR 1 is a Critical bHLH Regulator of Chlorophyll Biosynthesis. Science 2004, 305(5692):1937-1941.

doi:10.1186/1746-4811-7-30

Cite this article as: Zhang et al:: A highly efficient rice green tissue protoplast system for transient gene expression and studying light/ chloroplast-related processes. Plant Methods 2011 7:30. 